\title{
Vitamin $D$ and upper respiratory tract infections in young active males exposed to cold environments
}

\author{
Joanna Orysiak ${ }^{1, A-F}{ }^{\oplus}$, John S. Fitzgerald ${ }^{2, D-F} \oplus$, Jadwiga Malczewska-Lenczowska ${ }^{3, B, E-F}{ }^{\oplus}$, \\ Konrad Witek ${ }^{3, \mathrm{~B}, \mathrm{E}-\mathrm{F} \oplus}$, Jan Gajewski ${ }^{4, \mathrm{C}, \mathrm{E}-\mathrm{F} \oplus}{ }^{\text {, Agnieszka Zembron-Lacny }}{ }^{5, \mathrm{~B}, \mathrm{E}-\mathrm{F} \oplus \text {, }}$ \\ Barbara Morawin ${ }^{5, \mathrm{~B}, \mathrm{E}-\mathrm{F} \oplus}$, Dariusz Sitkowski ${ }^{3, \mathrm{E}-\mathrm{F} \odot}$ \\ ${ }^{1}$ Central Institute For Labour Protection-National Research Institute, Warsaw, Poland \\ 2 University of North Dakota, Grand Forks, USA \\ ${ }^{3}$ Institute of Sport - National Research Institute, Warsaw, Poland \\ ${ }^{4}$ Józef Piłsudski University of Physical Education, Warsaw, Poland \\ ${ }^{5}$ Collegium Medicum, University of Zielona Gora, Poland \\ A - Research concept and design, B - Collection and/or assembly of data, C - Data analysis and interpretation, \\ $D$ - Writing the article, E - Critical revision of the article, F - Final approval of article
}

\begin{abstract}
Orysiak J, Fitzgerald JS, Malczewska-Lenczowska J, Witek K, Gajewski J, Zembron-Lacny A, Morawin B, Sitkowski D. Vitamin D and upper respiratory tract infections in young active males exposed to cold environments Ann Agric Environ Med. 2021; 28(3): 446-451. doi: 10.26444/ aaem $/ 127530$
\end{abstract}

\section{Abstract}

Introduction and objective. Performing indoor and outdoor work in cold environments may result in various adverse effects on human health and may lead to increased risk of respiratory infection. The aim of this study was to determine the relation of vitamin D status to secretory immunoglobulin A concentration, leucocyte counts, cytokine concentrations and incidence of upper respiratory tract infection (URTI) episodes in young active men during an autumn-winter period.

Materials and method. The effect of work in a cold microclimate was studied among 23 young active male ice hockey players during a 19-week study period. Blood and saliva samples were collected 7 times during the study period. Incidence of URTI was evaluated using WURSS 21. White blood cell, neutrophil, lymphocyte, monocyte, eosinophil and basophil counts, concentrations of $25(\mathrm{OH}) \mathrm{D}, \mathrm{C}$-reactive protein, cortisol, IL-1ra, IL-10, IL-1 $\beta$ and immunoglobulins A, M and G, were determined in the blood. Secretory immunoglobulin A, A1 and A2 and cortisol were analysed in saliva. Spearman's correlations were used to evaluate relationships between initial or final $25(\mathrm{OH}) \mathrm{D}$ concentration and URTI incidence, as well as the immune and endocrine markers. Differences in URTI episodes, immune and endocrine parameters between sufficient $\left(\geq 20 \mathrm{ng}^{\circ} \mathrm{ml}^{-1}\right)$ and deficient $\left(<20 \mathrm{ng} \cdot \mathrm{ml}^{-1}\right)$ vitamin D status groups were compared with the Mann-Whitney test.

Results. There were no statistically significant correlations between mucosal and blood markers or URTI incidence and initial and final 25(OH)D concentrations. Immune, endocrine and URTI variables did not differ between deficient and sufficient vitamin $\mathrm{D}$ status groups.

Conclusions. 25(OH)D concentration has no impact on mucosal and systemic immunity, nor on URTI episodes.

\section{Key words}

secretory immunoglobulin A, 25(OH)D concentration, URTI, white blood cells, cytokines, mucosal immune system

\section{INTRODUCTION}

Performing indoor and outdoor work in cold environments may result in various adverse effects on human health - cardiovascular, respiratory, musculoskeletal or dermatological injuries and/or illness may be worsened by cold exposure $[1,2,3,4,5]$. These health conditions may decrease physical performance and productivity, and increase the occurrence of accidents [1]. Numerous researchers have suggested that both exercise (i.e., physical work) and cold (e.g., air temperature below $12^{\circ} \mathrm{C}$ ) may be potentially immunosuppressive, and in combination may contribute to meaningful reductions in immunity and increased risk of respiratory infection, especially for people working in some occupations (e.g., construction, fishing, food processing) $[2,6,7,8,9]$. In line with this, it has been shown that people

Address for correspondence: Joanna Orysiak, Central Institute For Labour Protection - National Research Institute, Warsaw, Poland

E-mail: joory@ciop.pl

Received: 25.06.2020; accepted: 15.09.2020; first published: 30.10 .2020 working in cold environments suffer upper respiratory tract infections more frequently (URTI; including the common cold, pharyngitis, epiglottitis and laryngotracheitis) than the general population $[10,11]$, for which respiratory tract infections are the most frequent cause of illness $[12,13]$. Since URTI is highly prevelant, it is important to find markers linked - directly or indirectly - to these infections with the aim of performing future interventions to reduce the prevelance and/or duration of illness. There is evidence that because of their ability to modulate immune function, some micronutrients can help protect against, or even lessen the effects, of some infection/illness [14].

Many years ago, Smiley [15] hypothesized that the seasonality of URTI was due to fluctuations in the 'vitamine' found in foods and produced in humans upon exposure to sunlight. In accordance with this hypothesis, in a British population, the prevalence of respiratory infections (influenza, pneumonia, bronchitis or severe cold) exhibited a seasonal pattern in the opposite direction to the pattern for serum 25-hydroxyvitamin D (25[OH]D) concentration 
[16]. Each $4 \mathrm{ng} \cdot \mathrm{ml}^{-1}$ increase in $25(\mathrm{OH}) \mathrm{D}$ concentration was associated with a $7 \%$ lower risk of infection after adjustment for adiposity, lifestyle and socio-economic factors [16]. Moreover, a recent meta-analysis reported an inverse assoctiation between serum $25(\mathrm{OH}) \mathrm{D}$ concentration and acute respiratory tract infection risk [17]. This association seems biologically plausabily as the identification of the vitamin $\mathrm{D}$ receptor (VDR) in almost all immune cells provides evidence that vitamin $\mathrm{D}$ contributes to immune system functioning by regulating both adaptive and innate immunity [18]. It is possible that low vitamin D status may have a substantial impact on URTI incidence in general and special (e.g., athletes) populations as the majority of them did not have the optimal level of vitamin D $[19,20]$.

Frequency of URTI can be influenced by many factors (e.g., cold air, travel, nutrition, sleep, stress, workload and physical activity), so research examining relationships between $25(\mathrm{OH}) \mathrm{D}$ concentrations and immunological indicators affecting URTI are difficult to interpret [21]. Moreover, the lack of similar procedures, study design, group, and conditions in these studies often give divergent results [17]. The lack of unambiguous results highlights the need for more research in this area.

Research on the relationship between immune and nutritional indices and the frequency of infection may be difficult in a specific group of labourers. This is often a diverse group in terms of gender, age, workload and other areas of life (e.g., recreational physical activity, health status, eating habits, smoking status, alcohol use, place of residence and leisure time activity). All of these factors can affect the immune system, exposure to pathogens, and therefore the frequency of infection. The best group for this type of research would be the most homogeneous group one gender, at a similar age, with similar physical activity, exposed to similar pathogens, and with a similar health status. Recruiting professional young athletes from one school presents such an opportunity. These athletes had similar environmental exposures as they frequented the same school buildings, boarding school, training facilities and dinning establishments, and had similar time spent outdoors. The training and competition are undertaken in an indoor ice rink where they were permanently exposed to cold air and indoor pollution throught the whole study period, all of which also caused similar exposure to pathogens. The athletes had similar daily exposure to mental and physical stress (training load). Work in a cold environment can reflect on the physical activity and stress in this group. According to Bauer et al. [22], elite athletes provide a good research model. As the authors emphasized, studies in athletic cohorts can yield insights that would not be attainable in the general population where a typical wide range of environmental exposure, nutrition habits and physical activity may confound associations between nutrient and immune indicies and frequency of infection [22].

\section{OBJECTIVE}

The aim of this study was to determine the relationship between vitamin $\mathrm{D}$ status to mucosal immunity, white blood cell counts, cytokine concentrations, and incidence of URTI episodes in young active men during an autumn-winter period.

\section{MATERIALS AND METHOD}

Volunteers. Twenty-three male ice hockey players from an Athletic High School completed a 19-week study period (age $16.5 \pm 0.5$ years; body mass $76.6 \pm 8.8 \mathrm{~kg}$; height $180.7 \pm 6.6 \mathrm{~cm}$; fat mass $13.2 \pm 3.2 \%$ ), during which the subjects trained each weekday for 120-180 minutes, and played 1-2 matches on the weekends. At the ice rink where the volunteers trained, the air temperature was $4-5^{\circ} \mathrm{C}$. A health questionnaire was administed before subjects were enrolled in the study. This study includes some data previously presented [23], but our aims and analyses differ from the original work. The study was approved by the local Ethics Committtee and informed consent was obtained from all volunteers parents.

Blood and saliva collection. Data collection began in October and ended in March (a period without sun exposure in Poland). Blood and saliva samples were collected 7 times every 3-4 weeks during the study period. Specimen collection took place at the same time each week (07:00-09:00), because of the diurnal rhythms of some markers [24]. The athletes were instructed to fast and refrain from exercise 12 hours pior to the laboratory visit.

The procedure used for blood and saliva collection has been described in detail elsewhere [23]. Breifly, a blood sample from the antecubital vein was obtained and haematological assays were performed during each laboratory visit. Salivary samples were acquired using the passive dribble method after rinsing the mouth with plain water. Saliva samples were then centrifuged and frozen prior to analysis.

Vitamin D was analysed only at the start and end of the study period. Immune and endocrine markers were determined on all 7 occasions.

Blood assays. ADVIA 120 haematology analyzer (Siemens, Germany) was used to determine white blood cell (WBC), neutrophil, lymphocyte, monocyte, eosinophil and basophil counts. Concentrations of C-reactive protein (CRP) and immunoglobulins (Ig) A, M and G in serum were measured using the immunoturbidimetric method (Horiba Pentra 400, Japan).

Cortisol concentration in serum was determined using commercially available ELISA kits (DRG, Germany), according to the manufacturer's protocol.

Normal ELISA kits for interleukin-1 receptor antagonist (IL-1ra; R\&D System USA) and high-sensitivity ELISA kits for IL-1 $\beta$ and IL-10 (R\&D System USA) were used to measure their concentrations in accordance with the manufacturer's attached instructions.

Total serum 25(OH)D concentration was analysed using commercially available ELISA kits (DiA Source, Belgium) to assess vitamin D status. This kit is endorsed by the Vitamin D External Quality Assessment Scheme (DEQAS) Advisory Panel.

Saliva assays. Commercially available ELISA kits (DIAMETRA, Italy) were used to analyse secretory immunoglobulin A ( $\operatorname{Ig} \mathrm{A})$ and cortisol in saliva according to the manufacturer's protocol. Salivary sIgA1 and sIgA2 were determined using ELISA kits (Immun Diagnostic Germany) in accordance with the manufacturer's protocol. All assays were performed in duplicate. 
The saliva flow rate $\left(\mathrm{ml} \cdot \mathrm{min}^{-1}\right)$ was calculated by dividing the volume of saliva collected by the duration (minute) of the collection period. The salivary $\operatorname{sig} \mathrm{A} / \mathrm{sIgA} 1 / \mathrm{sIgA} 2\left(\mu \mathrm{g} \cdot \mathrm{min}^{-1}\right.$ or $\mathrm{U} \cdot \mathrm{min}^{-1}$ ) was determined by multiplying the absolute salivary sIgA/sIgA1/sIgA2 concentrations by the salivary flow rate.

Upper respiratory tract infection. Incidence and symptoms of URTI were evaluated using the illness-specific quality of life instrument WURSS 21 (short form of Wisconsin Upper Respiratory Symptom Survey) [25]. Team medical doctors also diagnosed URTI and had frequent contact with all volunteers. The daily WURSS summary scores (severity score) are calculated by summing scores of individual item scores (rated as $0=$ No symptoms, $1=$ Very mild, $3=$ Mild, $5=$ Moderate, 7 = Severe), excluding the first and last items $[23,25]$. Mean duration of URTI for each volunteer was determined from days with URTI symptoms divided by number of URTI diagnosis. The mean duration of URTI for each volunteer was then averaged to determine the mean duration of URTI for the testing group [23].

Body composition. Characteristics of the group body composition was determined by bioelectrical impedance (BIA) using a Tanita Body Composition Analyser MC-420 (Japan).

Statistical analysis. Statistical analysis was performed by the Statistica 10.0 programme. The Kolmogorov-Smirnov test was applied for assessing normal distribution of data. Non-parametric tests were used since the majority of immune and endocrine variables did not meet the criteria of normal distributions. Descriptive statistics were reported as means and standard deviations. Deficient and sufficient $25(\mathrm{OH}) \mathrm{D}$ concentrations were defined as less than 20 $\mathrm{ng} \cdot \mathrm{ml}^{-1}$ and above $20 \mathrm{ng} \cdot \mathrm{ml}^{-1}$, respectively $[26,27]$. Serum $25(\mathrm{OH}) \mathrm{D}$ concentrations at the start (initial) and end (final) of the study were compared using the Wilcoxon signed rank test. Spearman's correlations were used to evaluate relationships between $25(\mathrm{OH}) \mathrm{D}$ concentration and URTI incidence, duration and severity, as well as the immune and endocrine markers. Differences in URTI episodes, immune and endocrine parameters between sufficient and deficient vitamin D status groups in October were compared with the Mann-Whitney test [28]. The level of statistical significance was set at $\alpha=0.05$ and all tests were two-tailed.

\section{RESULTS}

Vitamin D status. In October, volunteers' mean serum $25(\mathrm{OH}) \mathrm{D}$ concentration was $22.2 \pm 5.6 \mathrm{ng} \cdot \mathrm{ml}^{-1}$ (range $12.5-$ $35.4 \mathrm{ng} \cdot \mathrm{ml}^{-1}$ ), and $16.0 \pm 6.3 \mathrm{ng} \cdot \mathrm{ml}^{-1}$ (range 6.0-30.5 ng. $\mathrm{ml}^{-1}$ ) in March; both values differed significantly $(p=0.001)$. In October, $39.1 \%(n=9)$ of the volunteers were vitamin $\mathrm{D}$ deficient $\left(<20 \mathrm{ng} \cdot \mathrm{ml}^{-1}\right)$. The remainder of the volunteers $(60.9 \% ; n=14)$ were sufficient (none had severe vitamin D deficiency $<10 \mathrm{ng}^{-\mathrm{ml}^{-1}}$ ). After winter (in March), $47.8 \%$ and $30.4 \%$ of the volunteers were vitamin D deficient, or sufficient, respectively. Severe deficiency $\left(<10 \mathrm{ng} \cdot \mathrm{ml}^{-1}\right)[20]$ was present in $21.7 \%$ of the volunteers after winter.

Upper respiratory tract infection incidence, severity and duration of symptoms. URTI were observed among $83 \%$ of volunteers during the study $(n=42)$. Of those with URTI, 13 of volunteers had at least 2 URTI incidences. Mean duration of URTI $-5.4 \pm 4.7$ days. Mean total symptom severity score $-13.9 \pm 20.5$.

Correlations between vitamin D and immune and endocrine markers. There were no statistically significant correlations between sIgA and its subclass concentrations or secretion rates, $\mathrm{WBC}$ and its population counts, interleukin concentrations, endocrine markers, and initial and final 25( $\mathrm{OH})$ D concentrations (Tab. 1).

Correlations between vitamin D and URTI. There were no statistically significant correlations between URTI incidence, duration of URTI, total symptom severity score and $25(\mathrm{OH})$ $\mathrm{D}$ concentration at the beginning or end of the study (Tab. 1).

Vitamin D status, immune and endocrine markers and URTI in sufficient and deficient vitamin $D$ groups. Immune, endocrine and URTI variables did not differ between deficient and sufficient vitamin D status groups $(p>0.05)$ (Tab. 2).

\section{DISCUSSION}

More than 27,000 Polish people working in hot or cold microclimates, over 10, 000 work in cold environments [29]. These workers are likely to experience immune perturbations due to the cold environments which may increase the risk of respiratory infections. It has been shown that URTI has a meaningful impact on work attendance [30]. In the USA, almost a half of employees miss workdays due to respiratory infections [30]. Similarly in Poland, respiratory tract infections are the number one reason for taking sick leave, accounting for 5.9 missed workdays per worker per year [31]. Moreover, additional productivity is lost among workers who attend the workplace while ill [30]. Ill workers are less effective at work than those who are healthy, and it has been speculated that costs associated with ill workers attending the workplace may be higher than costs related to sick leave [32]. Given the prevelance of respiratory infections and their impact on productivity, developing strategies to reduce the incidence of these infections would be likley to appeal to employers.

The importance of nutrition to reduce the incidence of respiratory infections is well known. This study aimed to investigate the relation of vitamin D status to immunity and incidence of URTI episodes in young active men. However, despite studies describing the effects of vitamin D status on the immune system and respiratory infections, the results of the current study showed something different. The main findings were twofold: 1) $25(\mathrm{OH}) \mathrm{D}$ concentration was not associated with immune and endocrine markers; 2) 25(OH) $\mathrm{D}$ concentration was not associated with URTI symptom incidence, their duration or severity.

Previous studies showed that changes in secretory immunoglobulin A (sIgA) concentration, and/or WBC counts and/or cytokine concentrations may be associated with increased URTI episodes [23,33]. In the present study, no associations were found between $25(\mathrm{OH}) \mathrm{D}$ concentration and any immune markers. In contrast, He et al. [34] found IL-10 and IFN- $\gamma$ concentrations were significantly higher in athletes with a high vitamin D status $\left(25(\mathrm{OH}) \mathrm{D}>32 \mathrm{ng} \cdot \mathrm{ml}^{-1}\right)$, 
Table 1. Correlations between $25(\mathrm{OH}) \mathrm{D}$ concentration and saliva and blood markers and URTI.

\begin{tabular}{|c|c|c|c|c|c|}
\hline Marker & & Initial concentration of $25(\mathrm{OH}) \mathrm{D}$ & $\mathrm{p}$ & Final concentration of $25(\mathrm{OH}) \mathrm{D}$ & $\mathrm{p}$ \\
\hline \multirow{3}{*}{$\begin{array}{l}\text { Upper respiratory } \\
\text { tract infections }\end{array}$} & URTI incidence & -0.018 & 0.934 & -0.095 & 0.665 \\
\hline & duration of URTI (days) & 0.054 & 0.808 & -0.100 & 0.648 \\
\hline & severity score & 0.029 & 0.896 & 0.100 & 0.649 \\
\hline \multirow{7}{*}{ Saliva indices } & slgA concentration $\left(\mu \mathrm{g} \mathrm{ml}^{-1}\right)$ & 0.013 & 0.954 & -0.229 & 0.294 \\
\hline & slgA1 concentration $(U)$ & -0.121 & 0.584 & -0.142 & 0.518 \\
\hline & cortisol concentration $\left(\mathrm{nmol} \mathrm{I}^{-1}\right)$ & -0.093 & 0.673 & -0.302 & 0.162 \\
\hline & saliva flow rate $\left(\mathrm{ml} \mathrm{min}{ }^{-1}\right)$ & -0.083 & 0.707 & 0.176 & 0.422 \\
\hline & slgA secretion rate $\left(\mu \mathrm{g} \min ^{-1}\right)$ & -0.102 & 0.644 & -0.196 & 0.371 \\
\hline & slgA1 secretion rate $\left(\mathrm{U} \mathrm{min}^{-1}\right)$ & -0.123 & 0.578 & -0.026 & 0.907 \\
\hline & slgA2 secretion rate $\left(\mathrm{U} \mathrm{min}^{-1}\right)$ & -0.066 & 0.764 & 0.000 & 0.998 \\
\hline \multirow{12}{*}{ Blood indices } & WBC count $\left(10^{9} \mathrm{I}^{-1}\right)$ & -0.228 & 0.295 & 0.124 & 0.573 \\
\hline & Neutrophil count $\left(\left.10^{9}\right|^{-1}\right)$ & -0.233 & 0.284 & 0.080 & 0.718 \\
\hline & Lymphocyte count $\left(10^{9} \mathrm{I}^{-1}\right)$ & -0.204 & 0.351 & 0.190 & 0.384 \\
\hline & Monocyte count $\left(10^{9} \mathrm{I}^{-1}\right)$ & -0.158 & 0.471 & -0.116 & 0.599 \\
\hline & Eosinophil count $\left(10^{9} \mathrm{I}^{-1}\right)$ & -0.015 & 0.946 & 0.401 & 0.058 \\
\hline & Basophil count $\left(\left.10^{9}\right|^{-1}\right)$ & 0.007 & 0.973 & 0.215 & 0.325 \\
\hline & Cortisol concentration $\left(\mathrm{nmol} \mathrm{I}^{-1}\right)$ & -0.208 & 0.342 & -0.354 & 0.098 \\
\hline & IgA concentration $\left(\mathrm{g} \mathrm{l}^{-1}\right)$ & -0.275 & 0.205 & 0.187 & 0.392 \\
\hline & $\operatorname{lgG}$ concentration $\left(\mathrm{g} \mathrm{l}^{-1}\right)$ & -0.308 & 0.152 & 0.035 & 0.875 \\
\hline & IgM concentration $\left(\mathrm{g} \mathrm{l}^{-1}\right)$ & -0.083 & 0.708 & 0.276 & 0.202 \\
\hline & IL-1 $\beta$ concentration $\left(\mathrm{pg} \mathrm{ml}^{-1}\right)$ & -0.073 & 0.740 & -0.093 & 0.672 \\
\hline & IL-1 ra concentration $\left(\mathrm{pg} \mathrm{ml}^{-1}\right)$ & -0.171 & 0.435 & 0.027 & 0.902 \\
\hline
\end{tabular}

compared to athletes with low status $\left(25(\mathrm{OH}) \mathrm{D}<16 \mathrm{ng} \cdot \mathrm{ml}^{-1}\right)$. In accordance with the results of the current study, in British athletes no relationship was found between 25(OH) D concentration and circulating numbers of total leukocytes, neutrophils, lymphocytes, monocytes, or sIgA concentration [28]. It is possible that vitamin D may modify the immunity and URTI risk via other vitamin D-dependent mechanisms (e.g., cathelicidin) [28].

Some studies have shown an inverse association between $25(\mathrm{OH}) \mathrm{D}$ concentration and respiratory infection incidence in general $[16,35]$ and athlete populations $[28,36]$. However, depending on the study, increased risks of URTI episodes or longer duration of infection were associated with a serum $25(\mathrm{OH}) \mathrm{D}$ concentration below $15 \mathrm{ng} \cdot \mathrm{ml}^{-1}$ [17], $16 \mathrm{ng} \cdot \mathrm{ml}^{-1}$ [37], $30 \mathrm{ng} \cdot \mathrm{ml}^{-1}$ [35], and $38 \mathrm{ng} \cdot \mathrm{ml}^{-1}$ [38]. In contrast, the current study failed to find an association between vitamin $\mathrm{D}$ and URTI episodes, duration or severity. In the volunteers in this study, the initial mean $25(\mathrm{OH}) \mathrm{D}$ concentration was $16.7 \mathrm{ng} \cdot \mathrm{ml}^{-1}$ (range $-12.5-19.7 \mathrm{ng} \cdot \mathrm{ml}^{-1}$ ) and $25.7 \mathrm{ng} \cdot \mathrm{ml}^{-1}$ (range - 20.8-35.4 ng. $\mathrm{ml}^{-1}$ ) in the deficient and sufficient groups, respectively. It is possible that the lack of variation in $25(\mathrm{OH}) \mathrm{D}$ concentration between groups may have reduced the ability to detect a relationship between vitamin D and URTI episodes, which is consistent with the findings reported by Scullion et al. [39]. It should be noted that the reduction in URTI risk achieved via vitamin D supplementation appears to be greater in cohorts with severe vitamin D deficiency $[17,40$, 41], which may also explain the lack of association between $25(\mathrm{OH}) \mathrm{D}$ concentration and URTI in the current study.
Thirty-nine percent of volunteers in the current study were vitamin $\mathrm{D}$ deficienct $\left(<20 \mathrm{ng} \cdot \mathrm{ml}^{-1}\right)$, despite data collection taking place in October (after the months of the greatest exposure to most sunlight). After the winter, almost half of the volunteers had vitamin D deficiency $\left(<20 \mathrm{ng} \cdot \mathrm{ml}^{-1}\right)$. Only 2 volunteers in October and one in March had a 25(OH)D concentration above $30 \mathrm{ng} \cdot \mathrm{ml}^{-1}$. This finding is consistent with other investigations in athletes $[19,42]$ and the general population $[20,43]$. In the Polish population, more than $50 \%$ of adults from Northern Poland examined in the first 6 weeks of autumn were vitamin D deficient $\left(<20 \mathrm{ng} \cdot \mathrm{ml}^{-1}\right)$ [43]. Moreover, Płudowski et al. [20] observed that $65.8 \%$ of Polish adults had a $25(\mathrm{OH}) \mathrm{D}$ concentration of less than $20 \mathrm{ng} \cdot \mathrm{ml}^{-1}$ in late winter and spring. Insufficient exposure to the sun, inadequate diet and/or lack of supplementation are likely explanations for the high prevalence of vitamin D defiency in the current cohort $[43,44]$. It seems that sun exposure in Poland does not guarantee vitamin D sufficiency or time spent in the sun is not enough; therefore, it is necessary to monitor $25(\mathrm{OH}) \mathrm{D}$ concentration regularly in order to prevent vitamin $\mathrm{D}$ deficiency.

The presented study has limitations. The small sample size limited the ability to detect associations; therefore, future studies utilizing larger cohorts of men and women are needed $[20,43]$. It was not possible to observe changes in $25(\mathrm{OH}) \mathrm{D}$ concentration throughout the entire study period during which URTI occurred due to only collecting blood samples at the beginning and end of the study. The volunteers declared that they did not use supplement vitamin $\mathrm{D}$, but 
Table 2. URTI incidence, mucosal and blood markers among different vitamin D status groups (Mean $\pm S D$ )

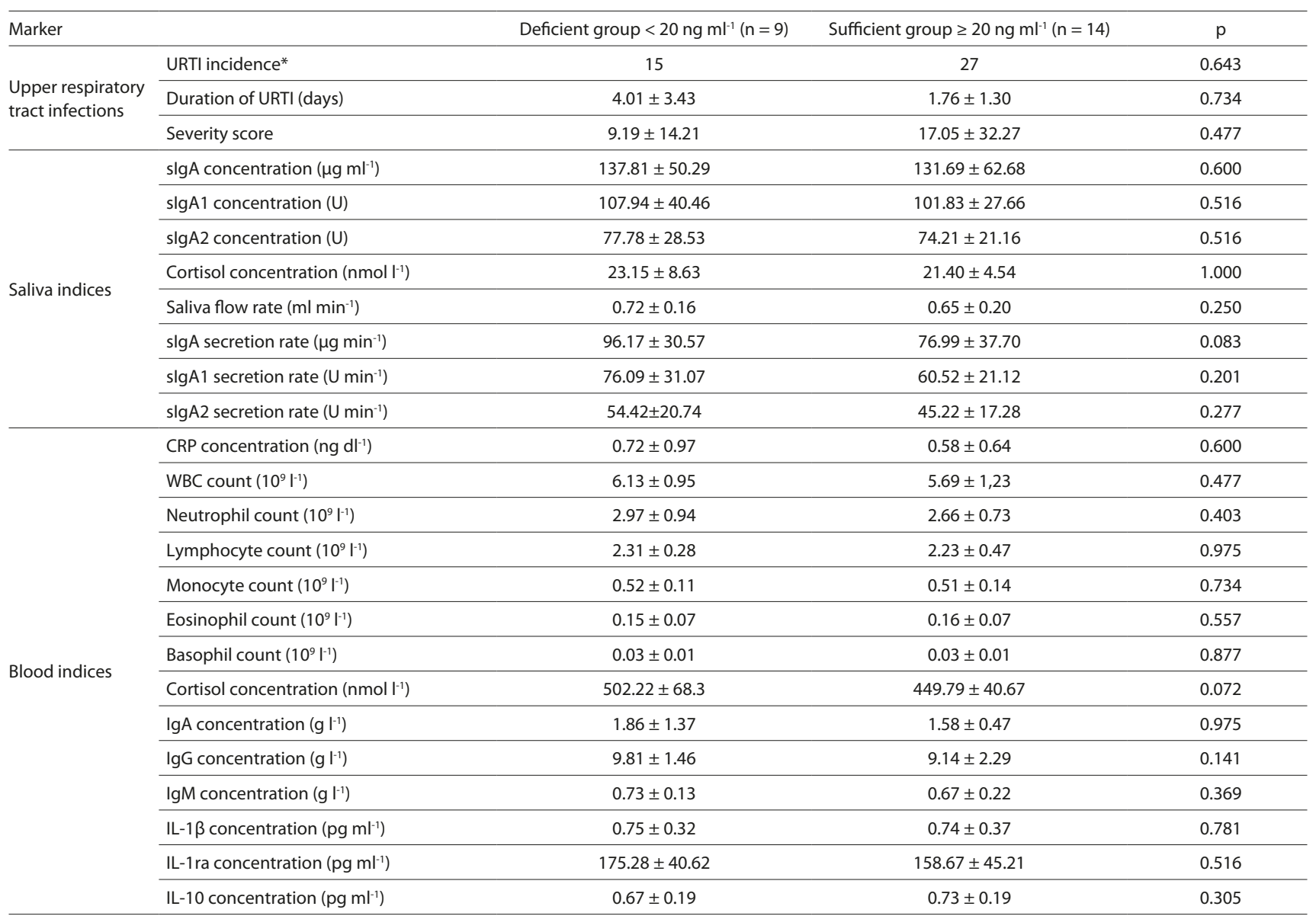

* values are expressed as sum.

dietary vitamin D intake was not assessed in this study; it was only known that everyone ate at the same school canteen with no choice of dishes. Moreover, only young men were examined who may not be generalized with older adults. However, young athletes, apart from the physiological and psychological stress caused by intensive training and pressure to achieve good results in competitions, have many educational, professional and personal obligations similar to adults [45]. Moreover, it seems that the mechanism of immunosuppression is similar in young people and may be generalizable to adults.

A major strength of this study was that all athletes were students from one ice hockey school and participated in a similar type and volume of training. The study was conducted in the period without sun exposure; therefore, confounding factors (training, diet and seasonality, as well as, exposure to pathogens) were minimized. Additionaly, volunteers completed validated questionnaires (WURSS 21) during the study period under the supervision of teachers, which improved the reliability and accuracy URTI questionnaire data.

\section{CONCLUSIONS}

In conclusion, $25(\mathrm{OH}) \mathrm{D}$ concentration was not associated with immune and endocrine markers, nor was it associated with URTI incidence, duration or severity of symptoms in young, active males. The results obtained suggest that $25(\mathrm{OH})$ $\mathrm{D}$ concentration (at least in the range $12.5-36.4 \mathrm{ng} \cdot \mathrm{ml}^{-1}$ ) has no impact on mucosal and systemic immunity, nor on URTI episodes. Therefore, the mechanism of action of vitamin $\mathrm{D}$ mobilizing the immune system and reducing the risk of upper respiratory tract infections still remains unknown. We found vitamin $\mathrm{D}$ deficiency to be highly prevalent in volunteers, confirming that sun exposure in Poland does not guarantee vitamin $\mathrm{D}$ sufficiency or the outdoor time between 10:00 and 15:00 during the vitamin D synthesis period is insufficient. A large proportion of the population works during these hours, which is why supplementation with vitamin $\mathrm{D}$ should be considered. Moreover, it appears necessary to monitor $25(\mathrm{OH}) \mathrm{D}$ concentration regularly in order to prevent vitamin $\mathrm{D}$ deficiency. Although vitamin $\mathrm{D}$ deficiency was not linked to immune function in this study, other negative effects of deficiency on health and physical performance can not be ruled out. Further research is needed to understand the influence of vitamin D on mucosal and systemic immunity, as well as, URTI incidence in cohorts with varing concentrations of $25(\mathrm{OH}) \mathrm{D}$.

\section{Acknowledgements}

The authors would like to thank the ice hockey players, their parents, coaches and teachers who participated in the study. The study was financially supported by the Ministry of Science and Higher Education Republic of Poland (Grant Nos. RSA2 006 52; 102.05). 


\section{REFERENCES}

1. Mäkinen TM, Hassi J. Health problems in cold work. Ind Health. 2009; 47(3): 207-220.

2. Cheung SS, Lee JK, Oksa J. Thermal stress, human performance, and physical employment standards. Appl Physiol Nutr Metab. 2016; 41(6 Suppl 2): S148-164. doi: 10.1139/apnm-2015-0518

3. Mohammadi D, Zare Zadeh M, Javad Zare Sakhvidi M. Short-term exposure to extreme temperature and risk of hospital admission due to cardiovascular diseases. Int J Environ Health Res. 2019. doi: 10.1080/09603123.2019.1663496

4. Luan G, Yin P, Wang L, et al. Association between ambient temperature and chronic obstructive pulmonary disease: a population-based study of the years of life lost. Int J Environ Health Res. 2019; 29(3): 246-254. doi: 10.1080/09603123.2018.1533533

5. Pecyna A, Buczaj A, Lachowski S, et al. Occupational hazards in opinions of forestry employees in Poland. Ann Agric Environ Med. 2019; 26(2): 242-248. doi: 10.26444/aaem/106246

6. LaVoy EC, McFarlin BK, Simpson RJ. Immune responses to exercising in a cold environment. Wilderness Environ Med. 2011; 22(4): 343-351. doi: 10.1016/j.wem.2011.08.005

7. Wang Y, Zhan S, Liu Y, et al. Occupational hazards tohealth of port workers, Int J Occup Saf Ergon. 2017; 23(4): 584-588. doi: 10.1080/10803548.2016.1199501

8. D'Amato M, Molino A, Calabrese G, et al. The impact of cold on the respiratory tract and its consequences to respiratory health. Clin Transl Allergy. 2018; 8: 20. doi: 10.1186/s13601-018-0208-9

9. Fargnoli M, Lombardi M, Haber N, et al. Hazard function deployment: a QFD-based tool for the assessment of working tasks - a practical study in the construction industry. Int J Occup Saf Ergon. 2020; 26(2): 348-369. doi: 10.1080/10803548.2018

10. Dasaraju PV, Liu C. Infections of the Respiratory System. In: Baron S, editor. Medical Microbiology. 4th ed. Galveston (TX): University of Texas Medical Branch at Galveston. 1996. Chapter 93. Available from: https://www.ncbi.nlm.nih.gov/books/NBK8142/

11. Eccles R, Wilkinson JE. Exposure to cold and acute upper respiratory tract infection. Rhinology. 2015; 53(2): 99-106. doi: 10.4193/Rhin14.239

12. Kuchar E, Miśkiewicz K, Szenborn L, et al. Respiratory tract infections in children in primary healthcare in Poland. Adv Exp Med Biol. 2015; 835: 53-9. doi: 10.1007/5584_2014_34

13. Finley CR, Chan DS, Garrison S, et al. What are the most common conditions in primary care? Systematic review. Can Fam Physician. 2018; 64(11): 832-840.

14. Gombart AF, Pierre A, Maggini S. A Review of Micronutrients and the Immune System-Working in Harmony to Reduce the Risk of Infection. Nutrients. 2020; 12(1): pii: E236. doi: 10.3390/nu12010236

15. Smiley D. Seasonal factors in the incidence of the acute respiratory infections. Am J Hygiene. 1926; 6: 621-626.

16. Berry DJ, Hesketh K, Power C, et al. Vitamin D status has a linear association with seasonal infections and lung function in British adults. Br J Nutr. 2011; 106: 1433-1440. doi: 10.1017/S0007114511001991

17. Pham H, Rahman A, Majidi A, et al. Acute Respiratory Tract Infection and 25-Hydroxyvitamin D Concentration: A Systematic Review and Meta-Analysis. Int J Environ Res Public Health. 2019; 16(17): pii: E3020. doi: 10.3390/ijerph16173020

18. Greiller CL, Martineau AR. Modulation of the immune response to respiratory viruses by vitamin D. Nutrients. 2015; 7: 4240-4270. doi: 10.3390/nu7064240

19. Farrokhyar F, Tabasinejad R, Dao D, et al. Prevalence of vitamin D inadequacy in athletes: a systematic-review and meta-analysis. Sports Med. 2015; 45: 365-378. doi: 10.1007/s40279-014-0267-6

20. Płudowski P, Ducki C, Konstantynowicz J, et al. Vitamin D status in Poland. Pol Arch Med Wewn. 2016; 126(7-8): 530-539. doi: 10.20452/ pamw.3479

21. Walsh NP. Recommendations to maintain immune health in athletes. Eur J Sport Sci. 2018; 18(6): 820-831. doi: 10.1080/17461391.2018.1449895

22. Bauer P, Kraushaar L, Hölscher S, et al. Elite athletes as research model: vitamin D insufficiency associates with elevated central blood pressure in professional handball athletes. Eur J Appl Physiol. 2019; 119(10): 2265-2274. doi: 10.1007/s00421-019-04210-w

23. Orysiak J, Witek K, Zembron-Lacny A, et al. Mucosal immunity and upper respiratory tract infections during a 24-week competitive season in young ice hockey players. J Sports Sci. 2017; 35: 1255-1263. doi: 10.1080/02640414.2016.1218039

24. Jones KS, Redmond J, Fulford AJ, et al. Diurnal rhythms of vitamin $\mathrm{D}$ binding protein and total and free vitamin D metabolites. J Steroid Biochem Mol Biol. 2017; 172: 130-135. doi: 10.1016/j.jsbmb.2017.07.015
25. Barrett B, Brown RL, Mundt MP, et al. Validation of a short form Wisconsin Upper Respiratory Symptom Survey (WURSS-21). Health Qual Life Outcomes. 2009; 7: 76. doi: 10.1186/1477-7525-7-76

26. Hollis BW. Assessment and interpretation of circulating 25-hydroxyvitamin D and 1,25-dihydroxyvitamin D in the clinical environment. Endocrinol Metab Clin North Am. 2010; 39: 271-286. doi: 10.1016/j.ecl.2010.02.012

27. IOM. Institute of Medicine. Dietary Reference Intakes for calcium and Vitamin D. Washington, DC: The National Academy Press. 2011.

28. He CS, Handzlik M, Fraser WD, et al. Influence of vitamin D status on respiratory infection incidence and immune function during 4 months of winter training in endurance sport athletes. Exerc Immunol Rev. 2013; 19: 86-101.

29. Grzenia A, Kazanowska D, Kazimierowska-Wasiołek M, et al. Working conditions in 2018. Statistics Poland. Statistical Office in Gdańsk, Centre for Working Conditions Statistics, Pomeranian Centre for Regional Surveys. 2019.https://stat.gov.pl/files/gfx/portalinformacyjny/ pl/defaultaktualnosci/5476/1/13/1/warunki_pracy_w_2018.pdf (access: 2020.06.22)

30. Dicpinigaitis PV, Eccles R, Blaiss MS, et al. Impact of cough and common cold on productivity, absenteeism, and daily life in the United States: ACHOO Survey. Curr Med Res Opin. 2015; 31(8): 1519-1525. doi: 10.1185/03007995.2015.1062355

31. KarczewiczE,SikoraA.2019.Absencjachorobowaw2018roku.https://www. zus.pl/documents/10182/39590/Absencja+chorobowa+w+2018+roku. pdf/c70b0e4a-2f6f-dbb9-7dde-79cf6ca334f8 (access: 2020.06.22)

32. Hansen S, Zimmerman P, van de, Mortel T. Assessing workplace infectious illness management in Australian workplaces. Infect Dis Health. 2017; 22(1): 12-20.

33. Gleeson M, Bishop N, Oliveira M, et al. Respiratory infection risk in athletes: association with antigen-stimulated IL-10 production and salivary IgA secretion. Scand J Med Sci Sports. 2012; 22: 410-417. doi: 10.1111/j.1600-0838.2010.01272.x

34. He CS, Fraser WD, Gleeson M. Influence of vitamin D metabolites on plasma cytokine concentrations in endurance sport athletes and on multiantigen stimulated cytokine production by whole blood and peripheral blood mononuclear cell cultures. ISRN Nutr. 2014; 2014 : 820524. doi: 10.1155/2014/820524

35. Ginde AA, Mansbach JM, Camargo CAJr. Association between serum 25-hydroxyvitamin D level and upper respiratory tract infection in the Third National Health and Nutrition Examination Survey. Arch Intern Med. 2009; 169: 384-390. doi: 10.1001/archinternmed.2008.560

36. Halliday TM, Peterson NJ, Thomas JJ, et al. Vitamin D status relative to diet, lifestyle, injury, and illness in college athletes. Med Sci Sports Exerc. 2011; 43: 335-343. doi: 10.1249/MSS.0b013e3181eb9d4d

37. Laaksi I, Ruohola JP, Tuohimaa P, et al. An association of serum vitamin $\mathrm{D}$ concentrations $<40 \mathrm{nmol} / \mathrm{L}$ with acute respiratory tract infection in young Finnish men. Am J Clin Nutr. 2007; 86: 714-717.

38. Sabetta JR, DePetrillo P, Cipriani RJ, et al. Serum 25-hydroxyvitamin D and the incidence of acute viral respiratory tract infections in healthy adults. PLoS One. 2010; 5: el1088. doi: 10.1371/journal.pone.0011088

39. Scullion L, Baker D, Healey P, et al. No Association between Vitamin $\mathrm{D}$ and Acute Respiratory Tract Infections Amongst Elite New Zealand Rugby Players and Rowers. Int J Vitam Nutr Res. 2018; 88(1-2): 8-15. doi: 10.1024/0300-9831/a000285

40. Jung HC, Seo MW, Lee S, et al. Vitamin $\mathrm{D}_{3}$ Supplementation Reduces the Symptoms of Upper Respiratory Tract Infection during Winter Training in Vitamin D-Insufficient Taekwondo Athletes: A Randomized Controlled Trial. Int J Environ Res Public Health. 2018; 15(9): pii: E2003. doi: 10.3390/ijerph15092003

41. Martineau AR, Jolliffe DA, Greenberg L, et al. Vitamin D supplementation to prevent acute respiratory infections: individual participant data meta-analysis. Health Technol Assess. 2019; 23(2): 1-44. doi: $10.3310 /$ hta 23020

42. Krzywanski J, Mikulski T, Krysztofiak H, et al. Seasonal Vitamin D Status in Polish Elite Athletes in Relation to Sun Exposure and Oral Supplementation. PLoS One. 2016; 11: e0164395. doi: 10.1371/journal.pone.0164395

43. Kmieć P, Sworczak K. Vitamin D deficiency in early autumn among predominantly non-elderly, urban adults in Northern Poland $\left(54^{\circ} \mathrm{N}\right)$. Postepy Hig Med Dosw (Online). 2015; 69: 918-924. doi: $10.5604 / 17322693.1165194$

44. Backx E, van der Avoort C, Tieland M, et al. Seasonal Variation in Vitamin D Status in Elite Athletes: A Longitudinal Study. Int J Sport Nutr Exerc Metab. 2017; 27: 6-10. doi: 10.1123/ijsnem.2016-0177

45. Hellard P, Avalos M, Guimaraes F, et al. Training-related risk of common illnesses in elite swimmers over a 4 -yr period. Med Sci Sports Exerc. 2015; 47: 698-707. 